\title{
Vibration Analysis and Experimental Study of GIS Busbar Enclosure under Electric Force
}

\author{
Dingge Yang, ${ }^{1}$ Yuzhao Li $\mathbb{D}^{2},{ }^{2}$ Yanhua Han, ${ }^{1}$ Bin Ding, ${ }^{1}$ Liangshu Li, ${ }^{3}$ and Jingfeng Wu ${ }^{1}$ \\ ${ }^{1}$ State Grid Shaanxi Electric Power Research Institute, Xi'an 710100, China \\ ${ }^{2}$ School of Mechanical Engineering, Xi'an Jiaotong University, Xi'an 710049, China \\ ${ }^{3}$ State Grid Shaanxi Electric Power Company Limited, Xi'an 710048, China \\ Correspondence should be addressed to Yuzhao Li; yzhao_li@163.com
}

Received 26 August 2021; Revised 22 December 2021; Accepted 11 January 2022; Published 30 January 2022

Academic Editor: Giorgio Dalpiaz

Copyright ( 92022 Dingge Yang et al. This is an open access article distributed under the Creative Commons Attribution License, which permits unrestricted use, distribution, and reproduction in any medium, provided the original work is properly cited.

To explore the vibration response of the GIS busbar enclosure in a strong electric field, the electric force on the busbar enclosure was solved by the voltage in the circuit and the principle of virtual work. The vibration mode was obtained by finite element technology. Accordingly, the vibration response of the busbar enclosure was obtained by vibration analysis in the frequency domain, and the vibration acceleration of the busbar was monitored in the substation. The simulation results showed that the busbar enclosure was subjected to the electric force because of the fundamental voltage and harmonic voltages in the conductor. By coupling the radial electric force and the vibration mode, it was found that the vibration responses of the busbar enclosure at $100 \mathrm{~Hz}$ and $2900 \mathrm{~Hz}$ were greater than those at other frequencies. The experimental result showed that the frequency with the highest vibration amplitude was the same as that of the simulation result, and the vibration acceleration amplitude in the experiment and simulation at $2900 \mathrm{~Hz}$ was basically consistent, which verified the accuracy of the simulation result. The study shows that the GIS enclosure shell will produce vibration at the two times power frequency and high frequency, which provides an explanation for the high-frequency vibration of busbar shell structure in the ultra-high-voltage substation and provides an objective basis for the design of the busbar enclosure in the ultra-high-voltage substation.

\section{Introduction}

Gas-insulated switchgear (GIS) is widely used in highvoltage power system substations because of its compact size and high reliability [1]. A busbar is a device in the GIS substation that can transmit electricity. The busbar enclosure generates mechanical vibration under different excitation during the operation of GIS $[2,3]$. The high-frequency vibration of the equipment produces audible noise $[4,5]$, which can affect the physical and mental health of the staff. Low-frequency vibrations can loosen bolts, causing gas leaks and accidents [6]. It is of great engineering guiding significance to analyze the vibration of the busbar enclosure.

There are many factors that cause the GIS busbar enclosure to vibrate. Many scholars studied the influence of partial discharges [7], poor contact [8-10], and temperature distribution change $[11,12]$ on the busbar enclosure vibration. These fault conditions can cause the failure of the substation operation, so the research studies are helpful to study the reliability and life of the equipment. However, the main excitation in the substation is current and voltage, which leads to the vibration of the electric equipment in normal operating condition. Many scholars studied the vibration responses of the busbar under the action of the electromagnetic force generated by the power frequency current [13-16], and they considered that the electromagnetic force is the main cause of the busbar vibration. Bian et al. [17] explored the vibration response of the GIS busbar under the condition of eccentricity using power frequency voltage. Zhang et al. [18] considered that the vibration is caused by current and voltage excitation at the same time and proposed that it is easier for the busbar enclosure to vibrate in no load because of the high voltage in the ultrahigh-voltage substation. It is known that the electric force 
increases as the voltage rises, and the electric force is also related to the size of the busbar [18]. These research studies mainly focus on the vibration at $100 \mathrm{~Hz}$. However, there are few research studies on the generation principle of highfrequency vibration of power equipment under normal operating conditions. Through the on-site test of the faultfree substation, the high-frequency vibration of the busbar shell appears at $2900 \mathrm{~Hz}$, the cause of which is unknown. This phenomenon has not been encountered before. Therefore, it is needed to come up with an explanation for this phenomenon to provide an objective basis for the design of the busbar enclosure in the ultra-high-voltage substation.

This paper proposes an interpretation method to explain the cause of high-frequency vibration of the busbar shell. This paper is organized as follows. Section 1 first describes the busbar model and the radial electric force of the enclosure. Second, the vibration responses in the simulation and experiment are obtained in Section 2. The conclusions are obtained in Section 3. The results show that the vibration responses in the simulation and experiment are relatively consistent, indicating that the vibration of GIS busbar enclosure was caused by harmonic voltages in the circuit under the condition of no fault, which provides an explanation for the high-frequency vibration of busbar shell structure in the ultra-high-voltage substation.

\subsection{Model of the GIS Busbar}

1.1.1. Busbar Model and Modal Analysis. The busbar model adopted in this paper is a three-phase divisional box used in $750 \mathrm{kV}$ GIS substation in northwestern China. The busbar model is shown in Figure 1, and the explosion model of the busbar is shown in Figure 2. The enclosure is outside the busbar, and the inside is a conductor. The two parts are connected by two basin-type insulators. The busbar enclosure is filled with $\mathrm{SF}_{6}$ gas inside and air outside. The material of the busbar enclosure and conductor is aluminum alloy 6063-T6. Young's modulus of elasticity $E=69 \mathrm{GPa}$, density $\rho=2700 \mathrm{~kg} / \mathrm{m}^{3}$, and Poisson's ratio $\mu=0.33$.

The size of the busbar enclosure is shown in Table 1.

The busbar enclosure was simplified to shell structure to facilitate the calculation. The parts simplified had less influence on the dynamic characteristics of the busbar enclosure. The busbar shell is shown in Figure 3.

In Figure 3, it can be known that the size transition characteristic of the busbar enclosure is preserved, which is essential to the dynamic behaviour of the busbar shell. The model can be used to analyze the dynamic feature of the busbar enclosure.

1.1.2. Radial Electric Force. The voltage excitation state of GIS is the state of loading voltage but no current. The conductor is excited by fundamental voltage and harmonic voltages, busbar shell grounding. There is a potential difference between the conductor and busbar shell because of the no-load state of GIS, which causes electric field inside the busbar. Then, there are induced charges on the inner face of the shell, which are different from the charges on the

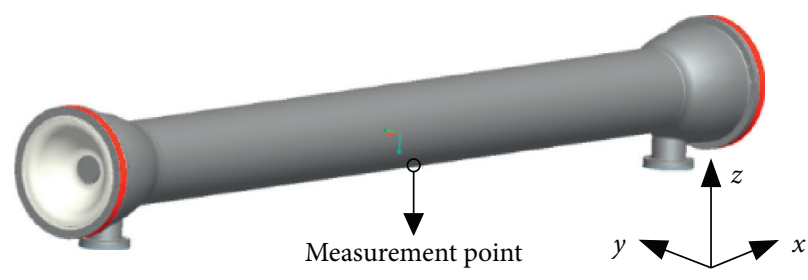

Figure 1: Busbar model.

conductor. The charges on the conductor and busbar shell cause the busbar to be subjected to electric force.

The electric force was solved based on five basic assumptions: (1) ignore the charge relaxation-the charge relaxation time of good conductor is much less than 1 ; (2) no charge inside the conductor-the charge is only distributed on the surface of the conductor; (3) ignore the magnetic field generated by the displacement current; (4) ignore the electric field generated by the polarization charge of $\mathrm{SF}_{6}$; and (5) ignore the influence of shell and conductor deformation on electric field distribution. As a long cylindrical shell structure, it is simplified to a two-dimensional cylindrical shell structure, as shown in Figure 4, which can be used to calculate the radial electric force on the busbar shell.

The voltage between the two cylindrical conductors per unit length [19] is

$$
U=\frac{\tau}{2 \pi \varepsilon} \ln \frac{R_{2}}{r_{1}},
$$

where $\tau$ is the charge of the conductor per unit length; $\varepsilon$ is dielectric constant of $\mathrm{SF}_{6}$, the relative dielectric constant is 1.002049 , and the vacuum dielectric constant is $8.854 \times 10^{-12} \mathrm{~F} / \mathrm{m} ; R_{2}$ is the inner radius of the busbar shell; and $r_{1}$ is the outer radius of the conductor. According to the principle of virtual work, the electric force of the busbar shell per unit length can be calculated:

$$
F=-\frac{\pi \varepsilon U^{2}}{R_{2}\left(\ln R_{2} / r_{1}\right)^{2}},
$$

where negative sign indicated that the direction of the radial electric force $\mathrm{F}$ was from the busbar shell to the conductor. We can calculate that the electric force increases as the voltage rises, and the electric force is also related to the size of the busbar. According to the assumption number two, we can know that the electric force on the inner face of the busbar shell is uniformed. The electric force per unit area, namely electric force density, can be obtained:

$$
p_{r}=\frac{\varepsilon U^{2}}{2 R_{2}^{2}\left(\ln R_{2} / r_{1}\right)^{2}},
$$

where $U$ is the potential difference between the busbar shell and the conductor. Equation (3) indicated that the electric force density can be obtained once the internal gas and the size of busbar are determined.

In this paper, the electric force density could be obtained using the measured harmonic voltage ratio in the substation. The ratio of first 60 harmonic voltages is shown in Figure 5.

Figure 5 shows that the power frequency $(50 \mathrm{~Hz})$ voltage ratio was $100 \%$, and the harmonic voltage ratio was low 


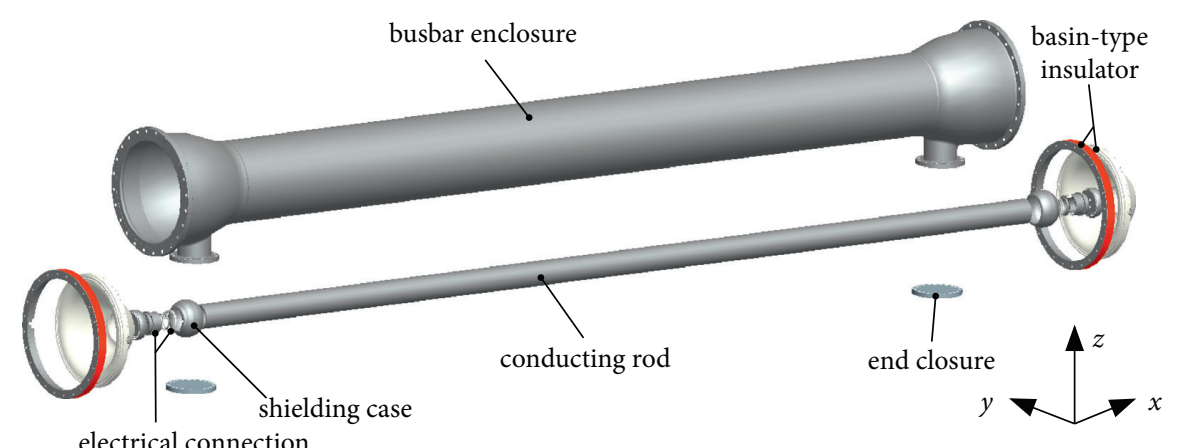

Figure 2: Explosion diagram of the busbar model.

TABLE 1: Dimension parameters of the busbar enclosure.

\begin{tabular}{|c|c|c|c|c|}
\hline $\begin{array}{l}\text { Conductor's outer } \\
\text { diameter } d_{1}(\mathrm{~mm})\end{array}$ & $\begin{array}{l}\text { Conductor's inner } \\
\text { diameter } d_{2}(\mathrm{~mm})\end{array}$ & $\begin{array}{c}\text { Busbar enclosure's outer } \\
\text { diameter } D_{1}(\mathrm{~mm})\end{array}$ & $\begin{array}{c}\text { Busbar enclosure's inner } \\
\text { diameter } D_{2}(\mathrm{~mm})\end{array}$ & $\begin{array}{l}\text { Busbar length } L \\
(\mathrm{~mm})\end{array}$ \\
\hline 180 & 150 & 600 & 584 & 7500 \\
\hline
\end{tabular}

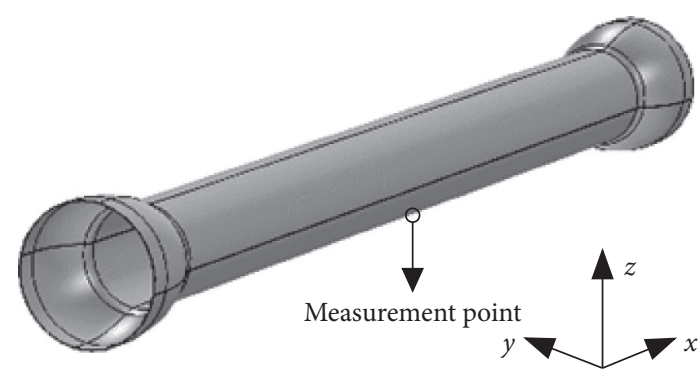

Figure 3: Structure model of the busbar shell.

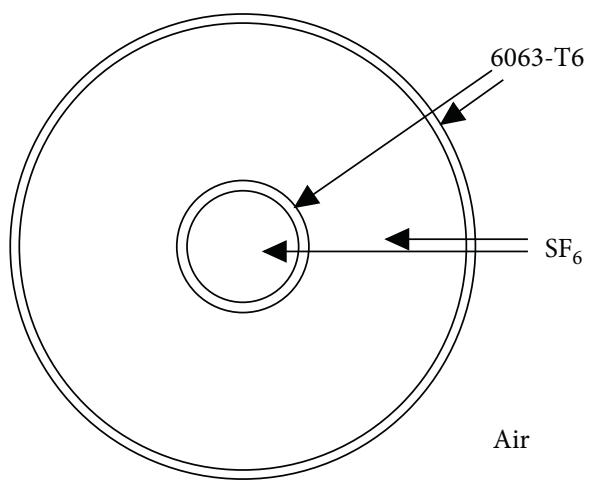

FIgURE 4: Two-dimensional busbar structure.

$(<1 \%)$. The total harmonic distortion rate of the first 60 harmonic voltages was $0.518 \%$, the odd distortion rate was $0.507 \%$, and the even distortion rate was $0.107 \%$. There is no clear requirement for the harmonic voltage ratio rate of the $750 \mathrm{kV}$ substation in the standard. According to the standard of the $110 \mathrm{kV}$ substation, the limit value of the total harmonic voltage distortion rate is $2 \%$, the limit value of the odd harmonic distortion rate is $1.6 \%$, and the limit value of the even harmonic distortion rate is $0.8 \%$. It was found that all

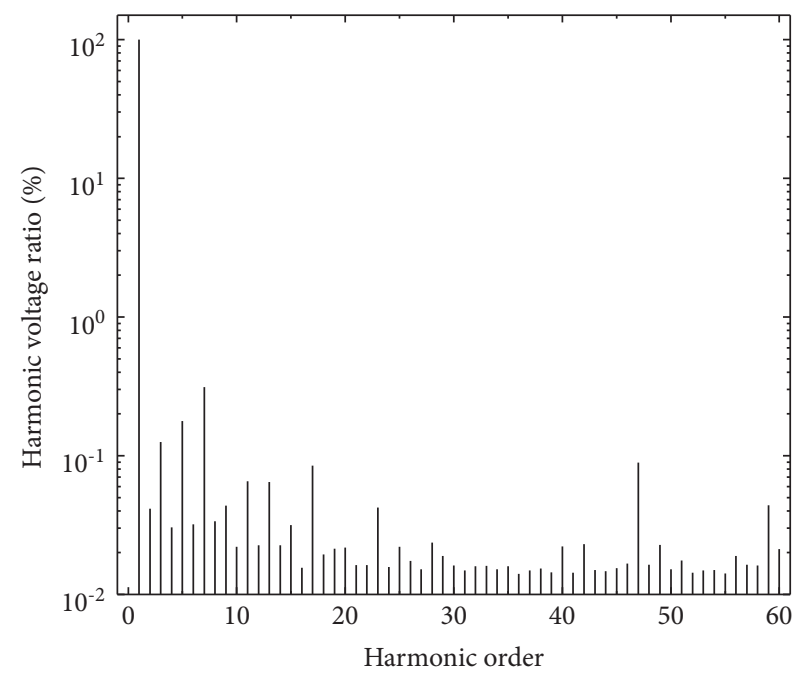

Figure 5: The first 60 harmonic voltages.

test results met the requirements. The data can be used to calculate the vibration response of the busbar shell.

The voltage in the time domain in conductor can be calculated using the ratio of first 60 harmonic voltages. Harmonic voltage ratio can be expressed as follows [20]:

$$
\mathrm{HRU}_{h}=\frac{U_{h}}{U_{1}} \times 100 \%,
$$

where $U_{1}=750 \times 1 / \sqrt{3}=433 \mathrm{kV}$ and the root mean square value of $h$-th harmonic voltage can be obtained using equation (4). The voltage superposition in the time domain was carried out using the following equation:

$$
U(t)=\sum_{h=1}^{60} \sqrt{2} U_{h} \sin (h \times 2 \pi f t) .
$$


The voltage in the time domain can be obtained as shown in Figure 6.

Figure 6 shows that the frequency of the voltage in the circuit was $50 \mathrm{~Hz}$. The electric force density on the busbar shell can be obtained using the voltage in the time domain, as shown in Figure 7.

Figure 7 shows that the frequency of the electric force density was $100 \mathrm{~Hz}$, which was two times the power frequency. The maximum amplitude of the electric force density was $14.04 \mathrm{~Pa}$ and the minimum was $0 \mathrm{~Pa}$. Fourier series expansion was used to transform the electric force density in the time domain to the electric force density in the frequency domain [21]:

$$
p_{r}(t)=\frac{a_{0}}{2}+\sum_{n=1}^{60}\left(a_{n} \cos (n \omega t)+b_{n} \sin (\omega t)\right),
$$

where

$$
\begin{cases}a_{n}=\frac{2}{0.02} \int_{0}^{0.02} p_{r}(t) \cos (n \omega t) \mathrm{d} t, & n=0,1,2,3, \ldots, 60 \\ b_{n}=\frac{2}{0.02} \int_{0}^{0.02} p_{r}(t) \sin (n \omega t) \mathrm{d} t=0, & n=1,2,3, \ldots, 60\end{cases}
$$

where maximum value of $n$ is 60 , that is, the maximum frequency of the harmonic voltages is $3000 \mathrm{~Hz} . \omega=100 \pi \mathrm{rad} /$ $s$. The electric force density in the frequency domain can be obtained as follows.

Figure 8 shows that the maximum of the electric force density was at $0 \mathrm{~Hz}$ and $100 \mathrm{~Hz}$, and the amplitude was $7.02 \mathrm{~Pa}$. The amplitudes of the electric force density at other frequencies were mostly below $0.01 \mathrm{~Pa}$. It was known that the busbar shell was subjected to electric force generated by the harmonic voltages of the conductor. We can solve the vibration response using the electric force and mode of the busbar shell.

\section{Results and Discussion}

2.1. Vibration Response in the Simulation. In COMSOL Multiphysics, we can obtain the results by numerical simulation. Applying fixed boundary at the both ends of the busbar shell for modal analysis, the vibration mode of the busbar shell within the range of $0 \sim 3000 \mathrm{~Hz}$ can be obtained. Among them, the mode shape of the busbar shell at $2883 \mathrm{~Hz}$ was special, which was the expansion-contraction deformation in the middle part, as shown in Figure 9.

The mode shape of the busbar shell at $2883 \mathrm{~Hz}$ was expansion-contraction deformation. When the frequencies of excitation and mode of the busbar shell were consistent, the busbar shell resonated. The mode shapes at other frequencies were complex and difficult to be excited, so they are not listed here.

The vibration response of the busbar shell can be obtained using the electric force density in the frequency domain and the mode of the busbar shell. The voltage is accurate at an integer multiple of $50 \mathrm{~Hz}$, so the frequency interval is $50 \mathrm{~Hz}$, and the frequency range is $50 \sim 3000 \mathrm{~Hz}$ in

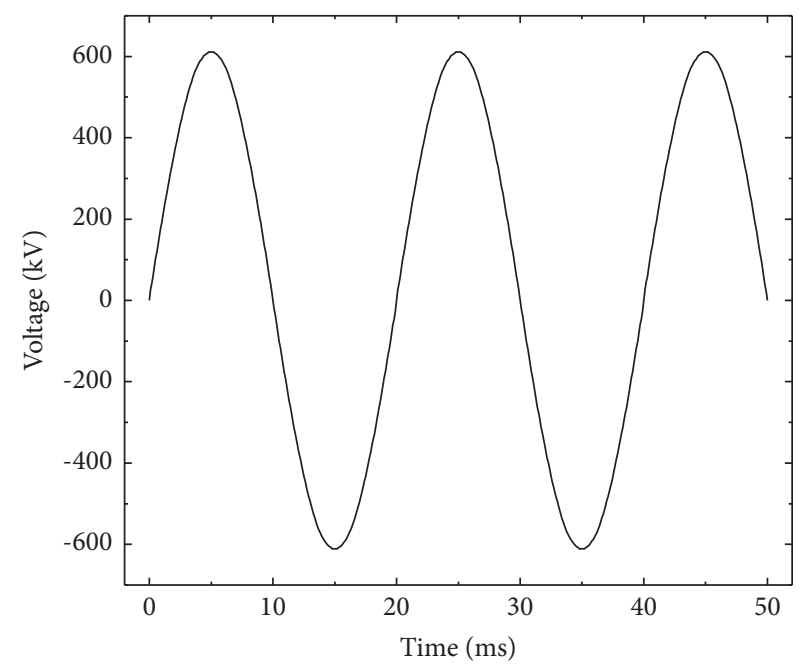

Figure 6: The voltage in the time domain.

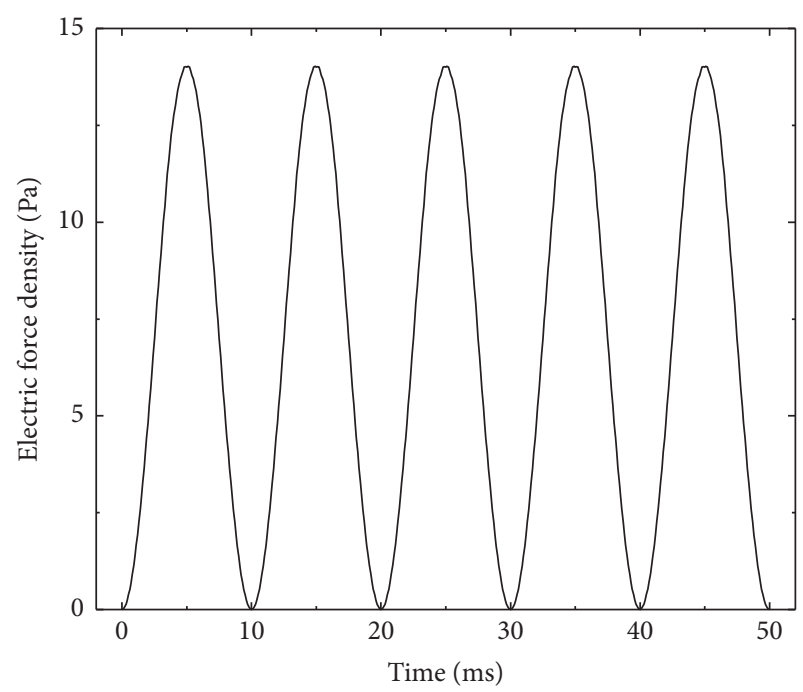

FIgURE 7: The electric force density in the time domain.

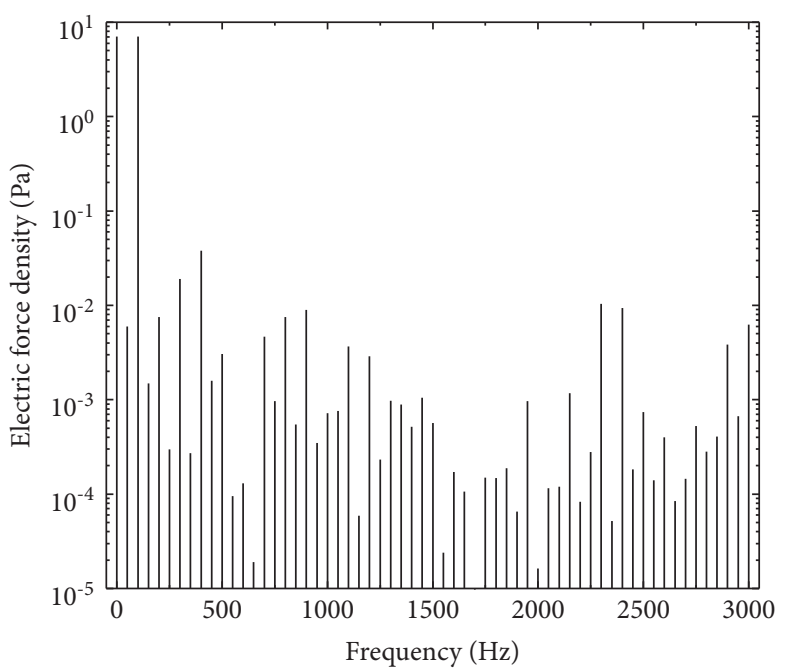

Figure 8: The electric force density in the frequency domain. 


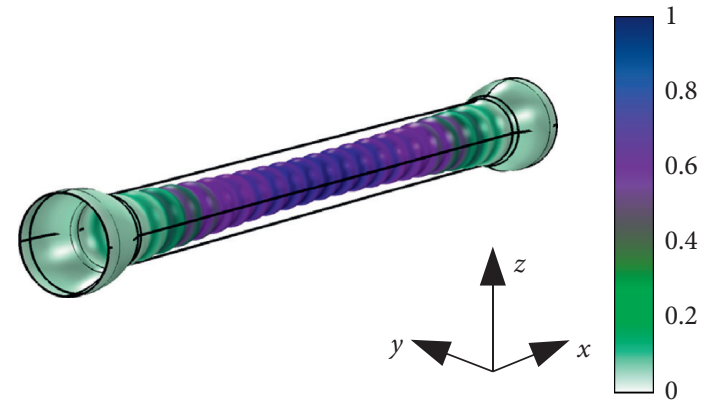

FIGURE 9: Expansion-contraction mode shape of the busbar shell at $2883 \mathrm{~Hz}$ in COMSOL.

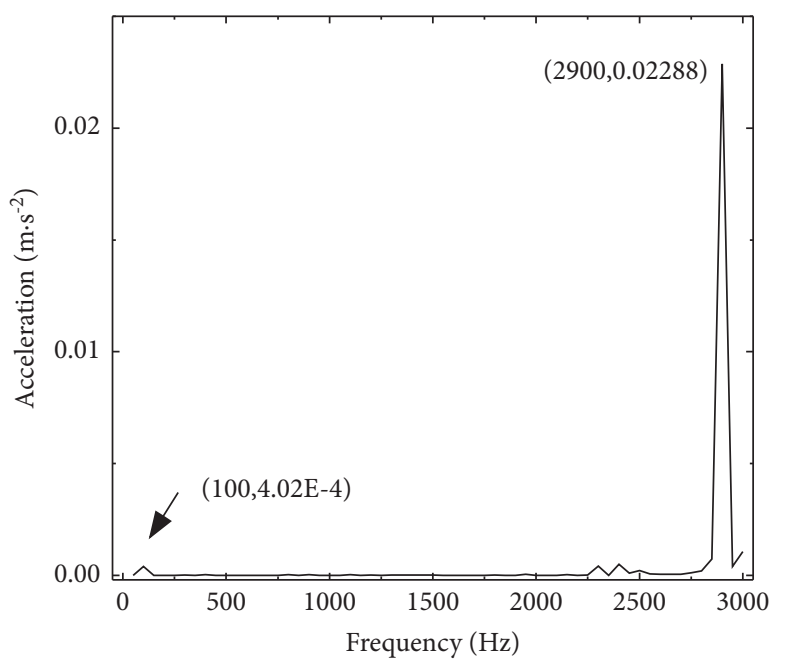

FIGURE 10: Radial vibration response of the busbar shell in COMSOL.

the process of solving. The modal damping loss factor considered in the calculations is 0.005 . The measurement point in the simulation is shown in Figure 3. The radial vibration response of the busbar shell can be obtained, as shown in Figure 10.

Figure 10 shows that the vibration amplitudes at $100 \mathrm{~Hz}$ and $2900 \mathrm{~Hz}$ were greater than those at other frequencies. At $2900 \mathrm{~Hz}$, the amplitude of radial vibration acceleration of the busbar shell was $0.02288 \mathrm{~m} / \mathrm{s}^{2}$. The amplitudes at other frequencies were close to zero. The deformation of the busbar shell at $2900 \mathrm{~Hz}$ is shown in Figure 11.

The reason why the busbar shell vibrated at $100 \mathrm{~Hz}$ was that the electric force density at $100 \mathrm{~Hz}$ was larger than that at other frequencies. The electric force density at $2900 \mathrm{~Hz}$ was very small, but the frequency of expansion-contraction mode was $2883 \mathrm{~Hz}$, which was near $2900 \mathrm{~Hz}$, so the vibration amplitude at $2900 \mathrm{~Hz}$ was very large. It can be judged that the vibration at $100 \mathrm{~Hz}$ was forced vibration, and the vibration at $2900 \mathrm{~Hz}$ was resonance.

Consistent results can be also obtained through numerical simulation in ANSYS Workbench. We can get the expansion-contraction mode shape of the busbar shell as shown in Figure 12, radial vibration response of the busbar

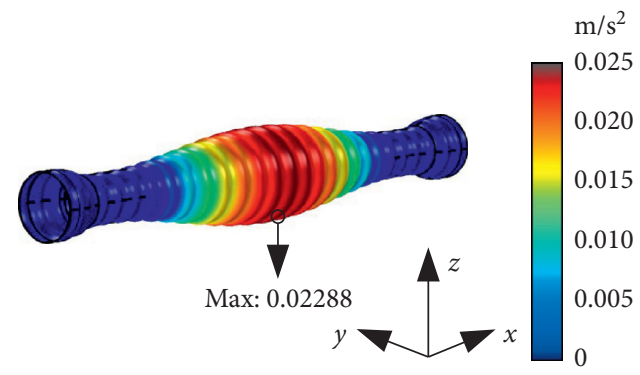

Figure 11: The acceleration of the busbar shell at $2900 \mathrm{~Hz}$ in COMSOL.

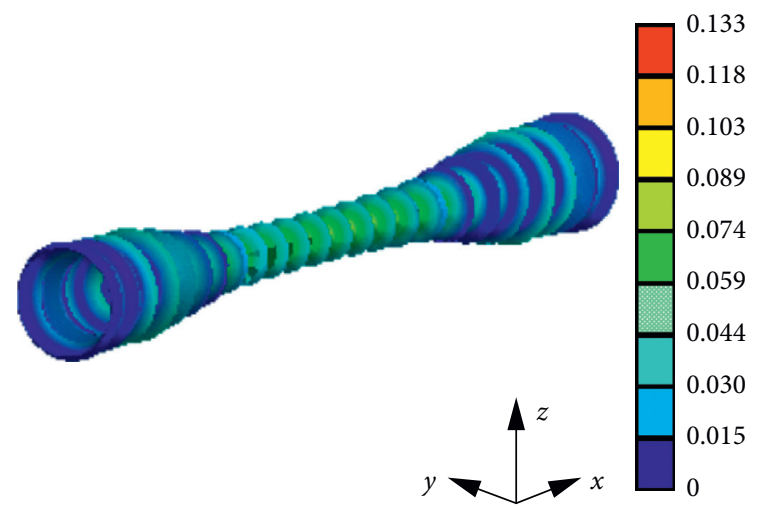

FIGURE 12: Expansion-contraction mode shape of the busbar shell at $2900 \mathrm{~Hz}$ in ANSYS Workbench.

shell as shown in Figure 13, and the acceleration of the busbar shell at $2900 \mathrm{~Hz}$ as shown in Figure 14. The results in ANSYS Workbench were the same as the results in COMSOL Multiphysics.

It can be known that the simulation results obtained by COMSOL Multiphysics and ANSYS Workbench are the same, so it can be known that the simulation results are correct. The vibration amplitude at $2900 \mathrm{~Hz}$ in COMSOL Multiphysics was $0.02288 \mathrm{~m} / \mathrm{s}^{2}$, and the result in ANSYS Workbench was $0.02249 \mathrm{~m} / \mathrm{s}^{2}$. The absolute deviation of vibration acceleration amplitude is $0.00039 \mathrm{~m} / \mathrm{s}^{2}$, and the relative error is $1.7 \%$, which is very small, so we can conclude that the results are correct.

2.2. Vibration Response in the Experiment. The radial vibration acceleration of the busbar enclosure in the actual operating condition was tested, and there was no fault inside the substation. The position of the measuring point is shown in Figure 1.

The equipment we used is the $\mathrm{m}+\mathrm{p}$ software and hardware. All of these are provided by $\mathrm{m}+\mathrm{p}$ international. The sensitivity of the sensor is $103.4 \mathrm{mV} / \mathrm{g}$. The sample rate is $12800 \mathrm{~Hz}$, and the useful bandwidth is $5000 \mathrm{~Hz}$. The block size is 1024 . The sample time is three seconds. The equipment in the scene is shown in Figure 15.

The spectrum of radial vibration acceleration in the range of $0 \sim 5000 \mathrm{~Hz}$ can be obtained, as shown in Figure 16. 


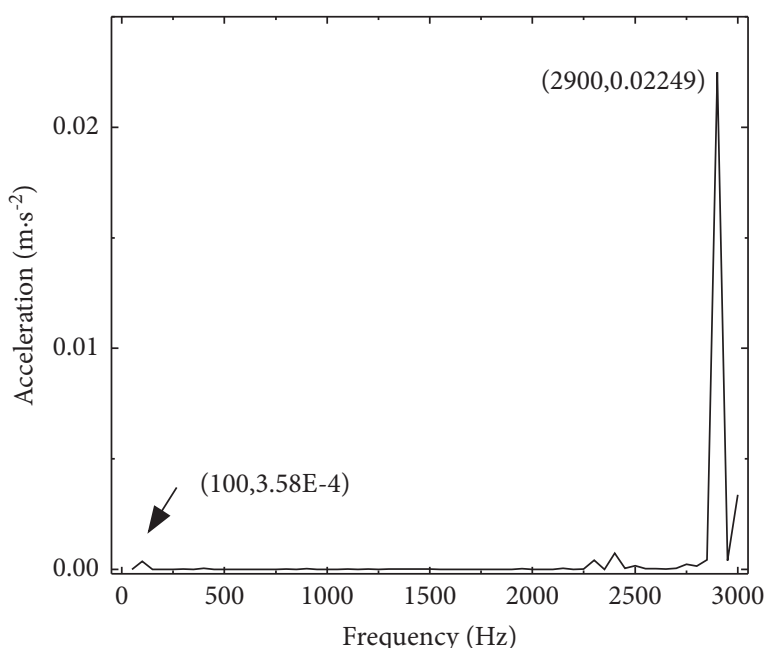

FIGURE 13: Radial vibration response of the busbar shell in ANSYS Workbench.

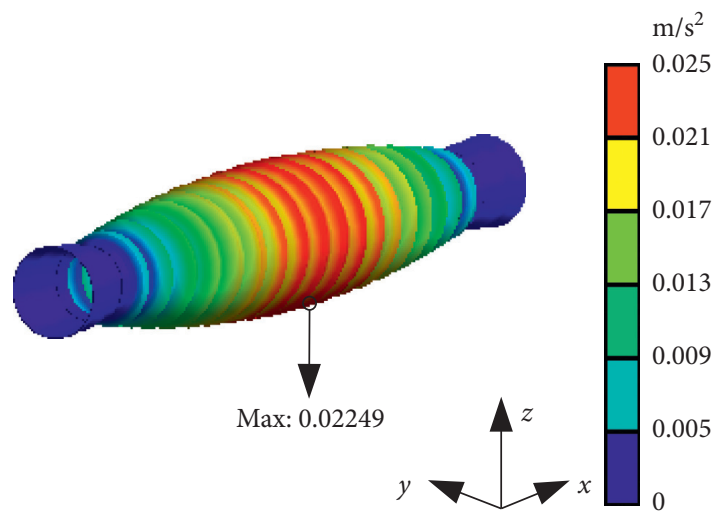

Figure 14: The acceleration of the busbar shell at $2900 \mathrm{~Hz}$ in ANSYS Workbench.

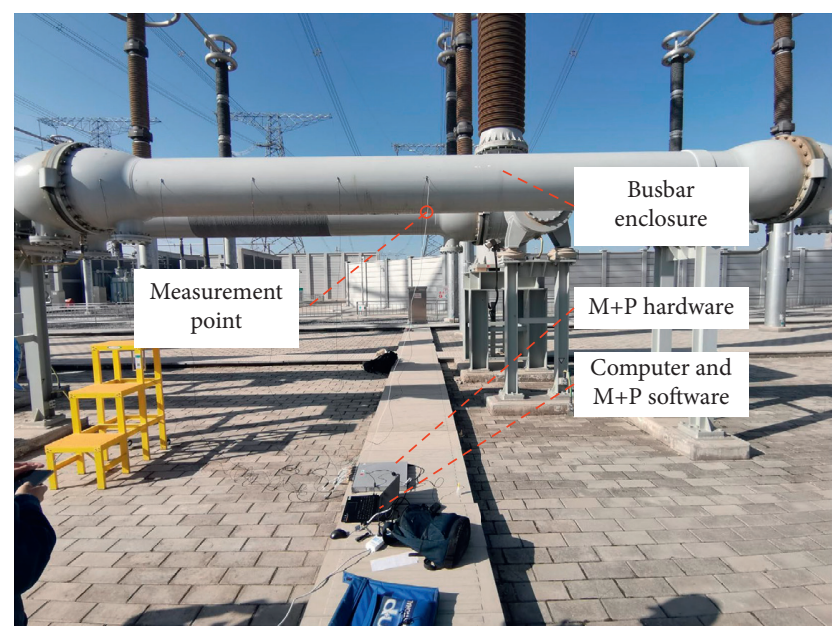

FIGURE 15: The equipment in the vibration test.

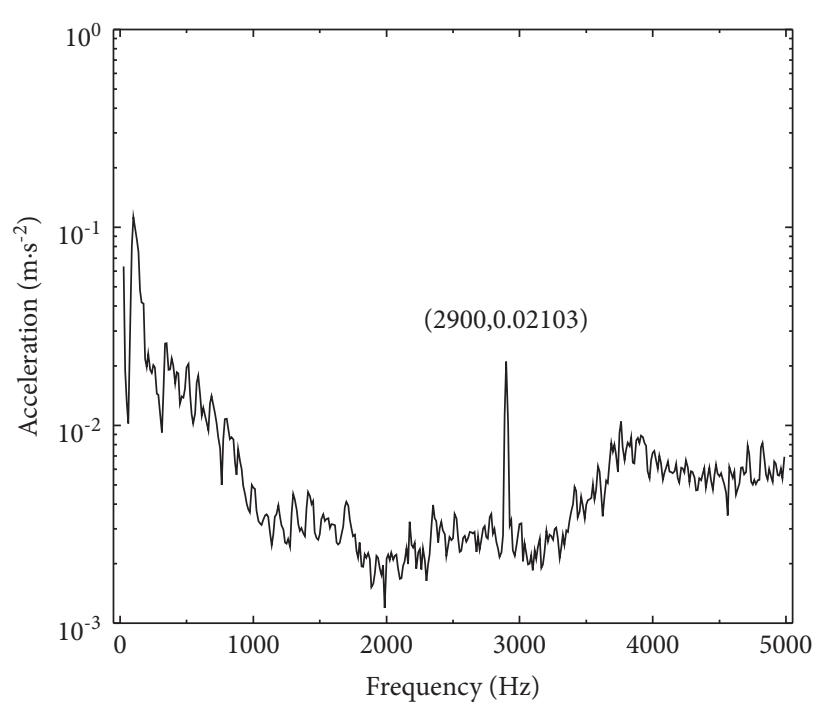

FIGURE 16: Radial vibration response of the busbar shell in the test.

Figure 16 shows that the frequency with the highest vibration amplitude in the experiment was $2900 \mathrm{~Hz}$, which was the same as the simulation result. The accuracy of the simulation result was verified. The simulation result showed that the vibration amplitude at $2900 \mathrm{~Hz}$ was $0.02288 \mathrm{~m} / \mathrm{s}^{2}$ in COMSOL Multiphysics and $0.02249 \mathrm{~m} / \mathrm{s}^{2}$ in ANSYS Workbench. In the experiment, the vibration amplitude at $2900 \mathrm{~Hz}$ was $0.02103 \mathrm{~m} / \mathrm{s}^{2}$. The relative error between the simulation and the experiment was $8.80 \%$ and $6.94 \%$, which was within the acceptable limit, indicating that the simulation was correct to a certain extent.

There were several reasons for the error between the simulation and experimental results. (1) The model simplification error: the busbar enclosure was simplified to shell structure, and there may be some differences in dynamic characteristics between the busbar shell and the actual busbar enclosure. (2) The vibration test error: the vibration results may be affected by the external environment in different ways. (3) The harmonic voltage test error: the harmonic voltage data were more accurate near the low harmonic, but the high harmonic data were rough, which led to the error of electric force density. (4) The effect of current in the circuit: in this paper, only voltage was considered, and the magnetic force generated by the current in the operating condition may also affect the vibration response.

Generally, the industrial equipment can generate the vibration at low frequencies because of the simple mode. At high frequencies, the mode shape is very complex, and the equipment is difficult to vibrate. However, the structure of the busbar enclosure is thin-shell structure, which has a special mode shape in the vicinity of $2900 \mathrm{~Hz}$. The mode shape is the expansion-contraction deformation as shown in Figures 9 and 12, which is similar to the electric force distribution. When the natural frequency of the expansioncontraction mode is close to the frequency of the electric force, the busbar enclosure can generate resonance, and the vibration amplitude is very large. 
In this case, the natural frequency of the expansioncontraction mode is in the vicinity of $2900 \mathrm{~Hz}$, and the radial electric force at $2900 \mathrm{~Hz}$ is large, so the vibration acceleration is very large at $2900 \mathrm{~Hz}$. By comparing the simulation with the experimental results, we can conclude that the electric force generated by the harmonic voltages can excite the mode of the busbar enclosure, causing the busbar enclosure to vibrate. When the amplitude of the electric force is large $(100 \mathrm{~Hz})$ or the electric force excitation frequency $(2900 \mathrm{~Hz})$ is close to the natural frequency with expansion-contraction deformation, the vibration response is large. We can know that the voltage is not the main factor, but the expansion and contraction mode of busbar shell structure is the main factor. The harmonic voltage content in the substation meets the standard requirements. The vibration occurred mainly because of the expansion and contraction mode at $2900 \mathrm{~Hz}$.

Using the same simulation steps, we can verify the vibration response of the product in the electric force to guide the product design. After the 3D model of the busbar shell is established, the mode is solved and the response can be obtained by applying electric field force to sweep frequency, and the existence of high-frequency vibration can be finally checked. If there is high-frequency vibration, the structure needs to be redesigned. If the high-frequency vibration is not obvious, the structure design is qualified.

\section{Conclusions}

In this study, based on the actual harmonic voltages in the circuit, the vibration response of the busbar enclosure was explored considering the electric force and mode of the busbar enclosure. By comparing the numerical results with the experimental results, it can be shown that the GIS enclosure shell will produce vibration at the two times power frequency and high frequency. From the results presented in this study, the following conclusions can be drawn:

(1) The busbar enclosure was subjected to electric force due to the presence of voltage in the conductor. Based on the data of the fundamental voltage and harmonic voltage ratio, we can calculate the voltage in the time domain, the electric force density in time domain, and the electric force density in the frequency domain in turn. The excitation on the busbar enclosure can be obtained.

(2) The busbar enclosure vibrated under the action of electric force. When the amplitude of the electric force was large $(100 \mathrm{~Hz})$ or the frequency of the electric force $(2900 \mathrm{~Hz})$ was close to the frequency with expansion-contraction mode shape, the vibration response was large. The vibration at $100 \mathrm{~Hz}$ was forced vibration, and the vibration at $2900 \mathrm{~Hz}$ was resonance.

(3) The test results showed that the frequency with the highest vibration amplitude in the experiment was the same as that of the simulation results, and the amplitude between the simulation and test results at $2900 \mathrm{~Hz}$ was basically consistent. The comparison results verified the accuracy of the simulation in this paper. It provides an explanation for the high-frequency vibration of busbar shell structure and an objective basis for the design of the busbar enclosure in the ultra-high-voltage substation.

\section{Data Availability}

The data used to support the findings of this study are available from the corresponding author upon request.

\section{Conflicts of Interest}

The authors declare that there are no conflicts of interest.

\section{Acknowledgments}

This study was supported by the Science and Technology Project of State Grid Shaanxi Electric Power Company Limited (5226KY20001G).

\section{References}

[1] T. Takeuchi, T. Yoshizawa, and Y. Kuse, "3-D nonlinear transient electromagnetic analysis of short circuit electromagnetic forces in a three-phase enclosure-type gas insulated bus," IEEE Transactions on Magnetics, vol. 36, no. 4, pp. 1754-1757, 2000.

[2] B. Qu, Y. Wang, L. Zhou, K. Wnag, and Z. Wang, "GIS vibration test method and characteristic signal recognition," Journal of Physics: Conference Series, vol. 1865, no. 2, Article ID 032021, 2021.

[3] K. Gholamreza, S. Keyhan, and H. Mohsen, "Multiphysics analysis of busbars with various arrangements under shortcircuit condition," IET Electrical Systems in Transportation, vol. 6, no. 4, pp. 237-245, 2016.

[4] Q. Xiong, J. Zhao, Z. Guo et al., "Mechanical defects diagnosis for gas insulated switchgear using acoustic imaging approach," Applied Acoustics, vol. 174, Article ID 107784, 2021.

[5] R. Ghosh, B. Chatterjee, and S. Dalai, "A method for the localization of partial discharge sources using partial discharge pulse information from acoustic emissions," IEEE Transactions on Dielectrics and Electrical Insulation, vol. 24, no. 1, pp. 237-245, 2017.

[6] Y. Zhong, J. Hao, R. Liao, X. Wang, X. Jiang, and F. Wang, "Mechanical defect identification for gas-insulated switchgear equipment based on time-frequency vibration signal analysis," High Voltage, vol. 6, no. 3, pp. 531-542, 2021.

[7] B. Liu, H. Ma, and P. Ju, "Partial discharge diagnosis by simultaneous observation of discharge pulses and vibration signal," IEEE Transactions on Dielectrics and Electrical Insulation, vol. 24, no. 1, pp. 288-295, 2017.

[8] Y. Yuan, S. Ma, J. Wu, B Jia, W Li, and X Luo, "Frequency feature learning from vibration information of GIS for mechanical fault detection," Sensors, vol. 19, no. 8, 2019.

[9] H. Ma, B. Liu, and H. Xu, "GIS mechanical state identification and defect diagnosis technology based on self-excited vibration of assembled circuit breaker," IET Science, Measurement \& Technology, vol. 14, no. 1, pp. 56-63, 2020.

[10] Y. Liu, J. Yang, and Y. Jia, "Connection state diagnosis method of GIS disconnector based on mechanical vibration," High Voltage Engineering, vol. 45, no. 05, pp. 1591-1599, 2019.

[11] S. Li, Y. Han, and C. Liu, "Coupled multiphysics field analysis of high-current irregular-shaped busbar," IEEE Transactions 
on Components, Packaging, and Manufacturing Technology, vol. 9, no. 9, pp. 1805-1814, 2019.

[12] J. You, Y. Wu, L. Wang, X. Liao, H. Liang, and L. Bao, "Thermal-dynamic stability analysis for the enclosed isolatedphase bus bar based on the subsegment calculation model," IEEE Transactions on Components, Packaging, and Manufacturing Technology, vol. 8, no. 4, pp. 626-634, 2018.

[13] Y. Feng and J. Wu, "Vibration feature analysis for gas-insulated switchgear mechanical fault detection under varying current," Applied Sciences, vol. 10, no. 3, 2020.

[14] X. Guan and N. Shu, "Electromagnetic field and force analysis of three-phase enclosure type GIS bus capsule," Applied Computational Electromagnetics Society Journal, vol. 29, no. 8, pp. 661-668, 2014.

[15] M. Szulborski, S. Lapczynski, L. Kolimas, R. D. Desire, and K. Lukasz, "Calculations of electrodynamic forces in threephase Asymmetric busbar system with the use of FEM," Energies, vol. 10, no. 20, 2020.

[16] K. Gholamreza, S. Keyhan, and H. Mohsen, "Coupled electric-magnetic-thermal-mechanical modelling of busbars under short-circuit conditions," IET Generation, Transmission \& Distribution, vol. 10, no. 4, pp. 955-963, 2016.

[17] C. Bian, Z. Zhang, K. Zhao, and T. Shu, "Study on mechanical vibration characteristics of GIS bus misalignment based on FEM,” High Voltage Apparatus, vol. 56, no. 6, pp. 72-79, 2020.

[18] S. Zhang, K. Zhang, and B. Yue, "Analysis on abnormal vibration and its time-varying force of GIS," High Voltage Apparatus, vol. 56, no. 10, pp. 155-160+167, 2020.

[19] N. Ida, Engineering Electromagnetics, McGraw Hill Press, New York, NY, USA, 2000.

[20] Gb/T 14549-1993, Quality of Electric Energy Supply-Harmonics in Public Supply Network, Standards Press of China, Beijing, China, 1993.

[21] S. Levent, Electromagnetic Modeling and Simulation, WileyIEEE Press, Piscataway, NJ, USA, 2014. 